\title{
Evolving Role of the Basic Science Course Director in an Integrated Curriculum
}

\author{
Emine Ercikan Abali • Neil Osheroff • \\ Engelbert Buxbaum • Eric C. Niederhoffer • \\ Karen Symes • Michel Sanders
}

Published online: 10 May 2014

(C) International Association of Medical Science Educators 2014

Over the last decade, traditional discipline-based curricula in medical and dental education are being gradually replaced by integrated and/or organ-based curricula. Some medical schools have completed this transition while others are moving in this direction. The LCME, the AAMC, and the Howard Hughes Medical Institute all support the use of integrated curricula as an approach to promote inquiry-based education, to increase retention of basic sciences knowledge, and to achieve a greater understanding of scientific principles behind

Contributors Emine Ercikan Abali, $\mathrm{PhD}$ is an Associate Professor of Biochemistry and Molecular Biology at the Rutgers Robert Wood Johnson Medical School, Piscataway, NJ, USA.

Neil Osheroff, $\mathrm{PhD}$ is an Professor of Biochemistry at the Vanderbilt University School of Medicine, Nashville, TN, USA.

Eric C. Niederhoffer, PhD is an Associate Professor of Biochemistry and Molecular Biology at the Southern Illinois University School of Medicine, Carbondale, IL, USA.

Karen Symes, PhD is an Associate Professor of Biochemistry and Assistant Dean of Student Affairs at the Boston University School of Medicine, Boston, MA, USA.

Engelbert Buxbaum is an Associate Professor of Biochemistry at the Ross University School of Medicine, Commonwealth of Dominica, West Indies.

Michel Sanders is a Professor of Biochemistry, Molecular Biology, and Biophysics at the University of Minnesota, Minneapolis, MN, USA

\section{E. Ercikan Abali $(\square)$}

Department of Biochemistry and Molecular Biology, Rutgers Robert

Wood Johnson Medical School, 675 Hoes Lane, Room \#527,

Piscataway, NJ 08854, USA

e-mail: abaliem@rwjms.rutgers.edu

\section{N. Osheroff}

Department of Biochemistry, Vanderbilt University School of

Medicine, Nashville, TN 37232-0146, USA

e-mail: neil.osheroff@vanderbilt.edu

E. Buxbaum

Department of Biochemistry, Ross University School of Medicine, Roseau, Commonwealth of Dominica, West Indies

e-mail: ebuxbaum@rossmed.edu.dm clinical practices. Many pre-clerkship course directors have embraced these changes with enthusiasm, since the clinical relevance of basic science subjects becomes very clear in an integrated curriculum. For example, in the new curriculum at Rutgers Robert Wood Johnson Medical School (RWJMS), the metabolism portion of biochemistry found a home in the GI, Metabolism, and Nutrition course, where students appreciate the relevance of biochemistry in a clinical context. However, with such major changes, there also come challenges. Here,

\section{E. C. Niederhoffer}

Department of Biochemistry and Molecular Biology, Southern Illinois University at Carbondale, Carbondale, IL 62901-4310, USA

\section{K. Symes}

Department of Biochemistry, Boston University School of Medicine, Boston, MA 02118, USA

e-mail: symes@bu.edu

\section{Sanders}

Department of Biochemistry, Molecular Biology and Biophysics, University of Minnesota, Minneapolis, MN 55455, USA 
five such challenges are discussed in the context of transitioning to an interdisciplinary curriculum: course direction; finding and evaluating facilitators; support for scholarly activity; negotiation between faculty, chairs, and deans; and faculty compensation.

The role and the responsibilities of the course directors have evolved during the transition from the traditional to integrated curricula. Under a discipline-based curriculum, the role and the responsibilities were well-defined and mainly guided by the department's chair. The course director was usually the content expert who developed the syllabus singlehandedly, and the chair determined the faculty who taught in the course. The chair allocated funds to the teaching mission, evaluated the teaching of the faculty, and proposed changes if necessary. The departmental chair also supported faculty development related to teaching and assessment. In an integrated curriculum, course directors have had to develop a new identity as medical educators who play an important role in consensus building to "buy-in" for the new curriculum and who create innovative interdisciplinary curricula with an emphasis on active learning. In this model, there is a steep learning curve awaiting course directors who must coordinate and collaborate with potential course co-director(s) from other basic science and clinical departments and/or other faculty from different disciplines and create small group active learning opportunities such as problem-based learning (PBL), team-based learning (TBL), and jigsaws. Course directors need to gain competency or find collaborators in other fields such as anatomy, physiology, and histology as well as physicians from a wide range of disciplines, in order to create a meaningful and integrated, clinically relevant, case-based course.

In addition, the simple lines of ownership and budget can become blurred in a medical school with a newly integrated curriculum. With curricular revision, establishing oversight and evaluation of the faculty from different disciplines (and often, different departments) becomes the responsibility of the course director(s). Although the new courses are interdisciplinary, most faculty members remain part of a discipline-based department. However, because in an integrated curriculum the department-based education is obsolete, there is a trend in medical schools to reduce the number of basic science departments, a trend that allows and supports the integrated nature of the curriculum. Often, evaluation and funding of the course now reside at a level higher than departments, most likely in the office of the associate dean of education or academic affairs. The budget to departments still may be distributed according to the relative contributions of faculty to the achievement of departmental missions. Consequently, while course directors have increased responsibility and challenges, they often have reduced power in implementing change.

The integrated curriculum overhaul is happening in the context of tightening budgets, with state budget shortfalls, and decreased NIH funding. It is complicated to tease out what is being done for strictly educational purposes (e.g., to increase student participation in their learning and help them integrate basic science and clinical material) and what is being done based on financial motivation (the elimination of departmental-based courses and establishment of a curriculum under a larger school-wide authority allows "consolidation" of basic science departments while leaving the teaching mission intact). The job of the course directors in this "new" curriculum is occurring in the context of this overall change in medical school organization and budget tightening, making it necessary for them to redesign the courses and recruit faculty in a changing culture and environment.

Comparisons of several institutions, including RWJMS, Southern Illinois University School of Medicine (SIUSOM), Boston University School of Medicine, Ross University School of Medicine, Commonwealth of Dominica, and University of Minnesota Medical School have yielded a number of models. The panel were all in agreement that many courses that appear as integrated and interdisciplinary are actually interdigitated, i.e., lectures from three or four courses from the discipline-base era are put together. At the University of Minnesota, biochemistry, genetics, nutrition, and development are integrated in a single course, Science of Medical Practice. Therefore, it is essential for basic science and clinical faculty to work closely together to fully integrate fundamental scientific knowledge into a clinical context. At Ross University, the spiral curriculum focuses on normal human body and functions in the first year and disease state in the second year. First-year course directors are basic scientists, and the secondyear course directors are clinicians, and there is coordination of course content between the first and the second year. Therefore, it is crucial to pair basic scientists with physicians whose expertise matches the content and to expect equal commitment from clinical course co-directors. However, due to physicians' schedules, the basic science course codirector(s) often do(es) most of the organizational tasks. The authors suggest that it may also be beneficial for the clinical course co-director(s) to attend educational meetings to increase understanding of each other's expertise for successful interdisciplinary teaching. It also may be worthwhile for the basic science course co-director(s) to have a shadowing experience with a clinical course co-director to enrich his/her understanding of the clinical scenarios that are used in active learning. For integrated curricula that are small-group centric, the natural tendency is built in for basic science and clinical medical interactions. However, in an active learning and an integrated curriculum setting, a greater number of faculty from different basic science and clinical disciplines are required as facilitators of small group activities. With the increased competition for obtaining grants and added demand on clinical faculty to bring more money into their institutions through clinical work, it is challenging to identify faculty facilitators 
unless percent effort can be provided. The questions then become, how do we get the faculty, department chairs, and the dean to provide support when the department does not have control of the course? And who supports and evaluates the faculty?

"Buy-in" for interdisciplinary curricula appears to be largely directed by a higher administrative level rather than the department. At Boston University School of Medicine, the dean charges the Medical Education Committee to build the curricular framework. Departmental and faculty "buy-in" for the new curriculum progresses through negotiation, where the course directors "sell" the process and content to the faculty through discussions. From this point on, at RWJMS, it is the course director's responsibility to identify basic science faculty from other departments and clinical faculty to help build an integrated course and to create a welcoming and professional environment to encourage their inclusion. At SIUSOM, educational matters are discussed and policies are developed by curriculum committees that have representation from basic science and clinical departments. Decisions are not made necessarily from a departmental perspective. As for identifying facilitators, course directors are using many creative sources to develop and recruit facilitators. For example, at RWJMS, an education elective for medical and $\mathrm{MD} / \mathrm{PhD}$ students was established. The use of non-faculty members to expand the pool of facilitators can accommodate the inclusion of small group sessions without depleting faculty and financial resources. Both the pre-clinical students and the $\mathrm{MD} / \mathrm{PhD}$ students benefit from this interaction. Pre-clinical students appreciate fourth-year medical students and $\mathrm{MD} / \mathrm{PhD}$ students for creating a collegial environment. In turn, the upper-class medical students enjoy being peer facilitators, since the small group sessions allow them to teach and refresh their clinical and basic science skills. Then again, this is not the case at all institutions. At SIU-SOM, which has been one of the pioneers of problem-based learning (PBL), upper-level medical students are used as facilitators, but find that the faculty facilitators have better skills when trained over a longer period of time and possess a significant experience with the process.

As medical school courses become more integrated, support for faculty development and other scholarly activities are falling under the purview of senior leadership in the medical school rather than under that of the department head. At Vanderbilt University, the Senior Associate Dean for Health Science Education strongly supports scholarly activities and faculty development and funds to support these activities come from a variety of sources. Furthermore, faculty with educational and curricular leadership roles receive "hard" development funds from the dean's office. Although departmental support is always welcome, in many respects, it is obsolete since the courses are "interdisciplinary" rather than "departmental," i.e., course directors represent the discipline as a content expert rather than the department. In the interdisciplinary and integrated curriculum, the educational goals of the basic science department and the educational goals of the institution are not always aligned. While many course directors find themselves grateful for or longing for a strong department chair's support, the others may find that chairs get in the way of establishing an interdisciplinary curriculum. However, this issue is less of a problem with many of the newer medical schools where basic science faculty are consolidated under a single combined organizational unit with teaching as the most important mission rather than in the traditional disciplinary based basic science departments.

It may be due to the fact many schools are in the transition stage of changing their curriculum, but there is a concern that many institutions lack transparency in their policies for faculty compensation, evaluation, and promotion. This can be particularly worrisome for faculty within basic science departments when departmental control of courses is lost. For example, what happens to the faculty member who is removed as course director due to poor performance or who was assigned as course director by the department chair as a result of losing laboratory funding? One model currently being used at Vanderbilt University is that faculty compensation is positiondependent and comes directly from the dean's office. It can include percent effort and development funds. This model, in which compensation comes directly from the dean's office, ensures that the percent effort goes to the faculty rather than the department. In cases of $100 \%$ educational faculty, appointments can be made from the Department of Medical Education, which is supported by the dean. At SIU-SOM, there exists an Educational Policy Committee. Compensation is determined by position description. Faculty performance is evaluated annually by the first-year curriculum director using the student evaluations and peer observation and with input from the department chair.

Many of us have similar concerns and issues at our institutions. Discussing shared experiences raises awareness of pertinent issues, which may guide us to be better course directors in interdisciplinary and integrated curricula and may also strengthen our relationship with our school administration.

Acknowledgements We thank Dr. Barbara Brodsky for proofreading the manuscript and providing thoughtful comments on the manuscript. 